\section{OUTCASTES IN AN "EGALITARIAN" SOCIETY: TAMANG/BLACKSMITH RELATIONS FROM TAMANG PERSPECTIVE ${ }^{1}$}

\author{
David Holmberg \\ Cornell University
}

It is now common to critique the social anthropology of South Asia as caught up in the essentialization (Appadurai 1988) of a "hierarchical" caste India and an "egalitarian" West, however, the terms of comparison are more complex. Critics of the Orientalist traditions of ethnological and historical scholarship on South Asia (cf. Appadurai 1988; Guha 1983; Dirks 2001) erase the place of "tribals" in colonial formulations of South Asia." The contrast between "tribes and castes," however, finds its way into innumerable gazetteers, ethnographic accounts, missionary ethnography, travelogues, and colonial reports well before the peak of the colonial ethnographic project of the late $19^{\text {th }}$ century. The comparison is not, as both the Orientalists and their postcolonial critics would have it, simply dialogical; they are at a minimum triangular. ${ }^{3}$ An opposition between hierarchical "caste" groups and egalitarian "tribes" has particularly structured the study of Nepal since the inception of ethnography there. Hodgson's first paper on "military tribes" in Nepal, for instance, was delivered in 1833 (Hodgson 1971 [1874]) to the Bengal Asiatic Society. Nepal emerged in anthropological imagination beginning in the early part of the $19^{\text {th }}$ century as a domain of tribals who by definition were understood in contrast to caste Hindus as more fundamentally "egalitarian." Brian Hodgson - the earliest systematic ethnologist of the Himalayan region describes the "tribes" of Nepal in these terms: "The whole population is tribal... But the barrier of caste, in the true sense, is unknown" (1874:32). This initial characterization had a substantial affect on subsequent anthropological work as the early professional anthropologist to enter Nepal in the 1950 s focused almost exclusively on non-caste populations (Sherpa, Gurung, Magar) to the neglect of other cultural ethnic groups.'

My concern in this paper is with an understanding of how "cgalitarian" Tamang have intimate and explicitly unequal relations with kami or Blacksmiths, the highest of the pani nacalne choi chito halmupame jat or castes from whom, in dominant Hindu perspective, one can not accept water and whose touch requires purification (Höfer 1979: 53-67). If one of the sacrosanct boundaries in the anthropologizing of Nepal is that between caste Ifindus and noncaste Tibeto-Burman speaking hill groups, how can the latter have caste? Moreover, if they do have "caste" how can they be egalitarian? My intent here is not to resolve these questions but to propose that our opposition between "hierarchical" and "egalitarian" may need to be reframed in different terms particularly those which look at systems of exchange and everyday interactions as they work in the production of cultural value. I am concerned less with questions of rank than with exchange relations especially those of symmetry and asymmetry and how they related to relations of domination and subordination (cf. Cameron 1998). I propose that Tamang govern their relations with Kami according to a different set of values or habitus (Bourdieu 1977) than Hindu caste villagers do theirs. Before turning to the specifics of Tamang/Kanni relations in the area where I worked in Nepal, let me bricfly reiterate the basis on which the egalitarian image of groups like the Tamang emanates.

\section{Tamang Egalitarianism}

It is largely in domains of marriage and commensality that concepts of hierarchy and equality take anthropological form in Nepal and South Asia. Western Tamang on the local level divide themselves into local patrician segments ${ }^{6}$. Until recently these patricians consistently practiced bilateral cross-cousin marriage with an announced preference for men to marry patrilateral cross-cousins or father's sister's daughters. The structural effect of these rules was to generate a regime that through time emerges as one of restricted symmetrical exchange among equal social segments. Although strict adherence to cross-cousin marriage is becoming modified in contemporary Nepal (Ahearn 2001), the logic of exchange in both practice and ideology - albeit of more generalized form 
- remains intact in Tamang kinship and social life. These practices produced social divisions in the western Tamang region that were not - in contrast to neighboring Hindu societics - ranked endogamous castes then but unranked exogamous clans and de facto moieties (Holmberg 1989a). Even where status asymmetries in Tamang communities have been documented (Fricke 1995), these status distinctions do not perpetuate as clear hierarchical divisions like those found in Hindu communities in Nepal or village North India where marriages have typically reproduced a ranked endogamous divisions among castes. Tamang commensality, like marriage, is markedly open and reciprocal in contrast to closed commensal practices found among caste oriented village populations in hill Nepal. As Toffin concludes: "Tamang society is fundamentally egalitarian." [my translation] (1986:42). Thus, the presence of lowly Blacksmiths in Tamang villages poses a contradiction to conventional representations.

\section{Kami in Tamang Villages}

In the western Tamang hamlets and villages to the Northwest of Trisuli Bazaar in Nuwakot, Rasuwa, and Dhading districts, households or clusters of households of Kami or untouchable Blacksmiths are found in villages otherwise dominated by Tamang. Kami along with sarki and damai are the three main $d$-lit or Untouchable groups (pani nacalne choi chito halnuparne jat) found in this hill region and many other areas of Nepal. There were no Sarki or Damai in the immediate area where I worked and they tended only to be attached to villages with high-caste Hindus. One can usually recognize these Kami households readily by their separateness and by their coating of black charcoal dust accumulated from activities associated with the working of iron in their forges. The documented sizes of Blacksmith settlements attached to Tamang villages varies from none or a few to upwards to one hundred. Ethnographers have generally neglected Kami and other outcaste communities (Sarki and Damai) in their concentration on dominant hill Tibeto-Burman speaking populations (cf. Gellner 1995). This neglect certainly characterizes my own research and I want to emphasize that my interpretation here is directed almost entirely toward the formal interactions of Tamang/Kami and toward Tamang views of Kami and not the inverse.' Thus, it is primarily about Tamang constructions of socioeconomic relations. It is about Kami to the extent that Tamang are the dominant group in the area where I worked and their perception of Kami constrains Kami life in significant ways. My material is drawn primarily from the village where I resided supplemented by the Andras Höfer's (1976) preliminary accounting of Kami social, ritual, economic, and technical life. Tamdungsa $a^{2}$ - the village of my research - had five households of Kami and 67 households of Tamang in the mid-1970s, a number that has not changed significantly in 30 years even though the number of Tamang households has increased dramatically.

Kami were and remain effectively landless and gained their livelihood through iron work for Tamang patrons or field labor for wealthier Tamang. Relations were structured on models similar to those we associate with the jajmani system of North India or what is commonly referred to the kamaune system of in hill villages of Nepal. Kami provided iron working service to Tamang patrons - whom Kami refer to as bista - for contractual amounts of millet, maize, and unhusked rice at the time of harvest. Relations between particular Kami and Tamang households tend to continue hereditarily and contracts are formally renewed annually. In addition to these agreed upon payments, Kami were entitled to meals at major ritual occasions (weddings, death feasts, sacrificial days, Dasain and the like) and receive special payments for major new tools. Most Kami find it hard to subsist on what they receive in retum for metal work and most must work in the fields of wealthier Tamang households in return for payments in grain. For instance, at the occasion of planting rice, one of the dominant Tamang households of the village in the late 1970s employed 14 Kami (along with Gurung and other Tamang) who received meals plus either grain or money. Some Kami in the region but not the village where I lived produce, in addition to iron tools, beaten copper vessels and aluminum wares on a cash basis. Some were also proficient as carpenters and were regularly employed in that capacity by Tamang households.

Although aspects of Tamang/Kami relations approximate those of the jajmani or kamaune system, there are notable differences. The most significant one is the absence of ritual service accompanying occupational contracts, a characteristic jajmani practices in Hindu 
villages. Tamang and Kami in fact live separate ritual lives despite their close economic relations. Kami replicate general Hindu practices with their own specialists- sometimes referred to, according to Höfer, as "Bahun." (1976:351). They do not participate in any major Tamang rituals or take blessings from Tamang Buddhist larnas. Kami jhankhri or shamanic specialists, however, often train with their Tamang counterparts - known as bombo - who are the undisputed masters of the spirit powers inhabiting the regional cosmos. More generally, the ritual life and obligations of Kami link them to other Kami communities in the region. The mother tongue of Kami is Nepali but they speak Tamang fluently. They also occasionally employ a "pig Latin" that Tamang are not supposed to understand. In their separateness, Kami remain, though, a ubicuitous presence in Tamang villages. They are always there at the margins of Tamang social rites getting their share of feasting foods or, on a more regular basis, begging, pleading, demanding, and cajoling food, tobacco, or raksi. It is in fact this characterization which plays elementally in Tamang constructions of them - an issue I will return to shortly.

\section{Pure/Impure in Tamang/Kami Interactions}

If asked Tamang will tell you that Kami are defiling and that if they are touched by a Kami that they must observe purificatory ritual. Toffin (1976:45) reports furher that vessels touched by Kami inust be ritually cleansed. Tamang refuse Kami entrance to their houses and will not accept cooked food or water from Kami hands. Kami and Tamang can not share the hookah and when men smoke together Kami receive the chilam part of the water pipe when alt others are finished ${ }^{3}$. Marriage is formally prohibited and sexual relations are not supposed to occur between Kami and Tamang. Kami squat on the verandas of Tamang houses and are not allowed to sit on raised benches. Inequality clearly structures interaction. I remember distinctly the return to the village of a Kami who had resided in Darjeeling for some time. Immediately upon his arrival to his home village in Nepal, he attempted to interact on an equal footing with Tamang. He sat on the benches reserved for Tamang and his demeanor was not subservient. The power of communal sentiment soon transformed this social hubris and in the matter of a few days, he was back to proper form, squatting on the floor cajoling in distinctively Kami style. Likewise, I had announced quite publically that I would not adhere to these sorts of strictures and that Kami were welcome in my living quarters, however, not one Kami ever attempted to enter my house the entire time I was resident in the village; they always sat outside even when explicitly invited inside. I, no doubt, was perceived as a temporary resident who was unable to mitigate or supercede pressure of local Tamang, especially my local patron in whose compound I lived. These strictures are familiar to anyone who has lived in hill Nepal and these practices appear to reflect an ideology of pure/impure and of necessary separation and hierarchy that we have come to associate with social practices of Hindu caste villagers.

Observers commonly explain the unequal relations between TibetoBurman speaking hill groups like Tamang and pani nacalne $j-t$ as a function of the historical contact with and subsequent acculturation to greater Hindu Nepalese society, what has been commonly referred to as the process of sanskritization. Tibeto-Burman speaking hill groups as Fürer-Haimendorf suggests for the Sherpa "imitate" (1972:14) high caste Hindus in their treatment of low castes. In other words, the contradiction of "outcastes" in otherwise ideologically egalitarian societies becomes a function of immigration of Blacksmiths into new areas and the dominance in Nepal of caste Hindus. There is, I believe, a modicum of truth in this assertion but I propose that there is more going on than simply acculturation to caste ideology. Although Tamang observe what appear to be rules similar to those we associate with caste relations in Hindu society, the nature of relations and their conceptualization are distinct.

Tamang do not have an elaborate set of restrictions surrounding purity and impurity (Dumont 1970) or inauspiciousness (Raheja 1988), values isolated by anthropologists in the analysis of transactions in Hindu society. Tamang do not elevate common pollutants to the socially charged significance they seem to carry for Hindus or for that matter even recognize them as pollutants (for instance, menstrual blood). Significant named pollutions (dip) are associated with birth and death and they are ritually cleansed almost immediately without lasting implication. ${ }^{4}$ In Dumont's (1970b) terms, all Tamang pollutions are "temporary." Tamang furthermore tend to handle the pollutions of death 
reciprocally and symmetrically. To the extent that people handle pollutions they do so in a direct give and take. For instance, the impurity acquired through contact with corpses and the personal effects of the deceased passes back and forth in Tamang society among affinal kin in a pattern whereby groups reciprocally defile each other. Although Tamang adhere to Hindu-like restrictions on commensality with non-Tamang, within Tamang society the emphasis is on exchanging food - including in some ritual instances food from a common receptacle - and not on restricting food. Kami may formally be said to defile one if touched, Tamang and Kami in fact touch with great regularity and in my experience, almost never perform purificatory rites even though most individuals can describe those rituals. I have watched young Tamang women and Kami women parade around in festivals with their arms around each other. I witnessed a senior and influential Tamang man have his torso massaged by a Kami without ill effect or ritual cleansing. Tamang, thus, gloss relations with Kami in a rhetoric of pure and impure but their relations are, I would argue, constructed on very different principles of exchange and meaning.

\section{Kami and Evil in Tamang Social Imagination}

Outcasting of one form or another is not, in fact, confined to Hindu society in Nepal or elsewhere. Hutton (1973[1946]:133-148) and Passin (1955) provide comparative evidence on caste practices elsewhere. In Nepal, Tibetans, Sherpa, Gurung, Thakali and others outcaste groups like Blacksmiths and Butchers. Tamang have close historical links to Tibet and we may be able to gain some comparative insights by examining their practices which appear to be structured differently in these societies. Aziz (1978: 58), for instance, makes the following observations:

. . . outcaste individuals in both Sherpa and Tibetan society have a chance (albeit a limited one) for upward mobility that will lift them into the mainstream of their society. Interaction is facilitated through commensality among all Tibetans including ya-wa [outcastes], who join public gatherings and are served food and liquor along with other guests. In addition to secular foods, ya-wa can also take ritual foods, votive offerings (tsog) distributed throughout the community.
Although both Sherpa and Tibetans view outcastes as defiling, this pollution is constructed very differently and gets linked with notions of the demonic and of evil. Ortner observes that in Sherpa symbology, "The lower castes as polluting seem best explained in terms of the demonic principle - violence and aggression - though sheer physicality also plays some role." (1973:55). Aziz reports a conversation with her cook about an outcaste man, "She [her cook] claimed he was evil, and when I retorted that in my dealings with him I had not found his so, she conceded with the remark, 'He's not too bad, but his kind of people are evil. All ya-wa are dangerous."” (1978:58).

Likewise Tamang imagine Kami to be not so much polluting but perpetually wanting, begging, and, by implication, inherently evil. Connotations of evil culturally supersede impurity or defilement in Tamang representations. Tamang are likely to accuse Kami of being boksi or witches, of keeping bir or familiars for the appropriation of wealth and vitality from others, or in female form, to capture the shadowsouls of young children. Tamang exorcists and sacrificers chant out the evils of "Sarkini, Damini, Kamini" - female representatives of hill outcastes - when curing or protecting children. Kami are not the only ones who are accused of being boksi or of keeping familiars (bir) or of being evil. Tamang accuse each other of such predilections as well as of being mengko or poisoners. Tamang, however, figure Kami as being inherently predisposed toward evil whereas Tamang are not; they must prove it through their accumulative and greedy actions, actions which defy the reciprocal ethos. To understand this formulation of Kami and ultimately how Tamang frame their interactions with Kami, we must see Kami in light of Tamang village social ideology and practice. Kami as social evils are constructed like spirit evils according to a logic which stresses inclusive reciprocity. Evil is for Tamang linked to those who are left out of symmetrical exchanges, those who do not receive their fair shares.

Much has now been written on the ethos of reciprocity among Tamang and related Tibeto-Burman speaking groups in Nepal and I will not elaborate on it here at great length. Tamang are well known for the hospitality accorded to their fellows as well as visitors. There is a sense embedded in lore and social practice that if you horde and do not share, 
your possessions will diminish and that if you share, they will expand. In the most ordinary circumstances and often with paltry resources, Tamang feel obliged to treat guests with food, drink, tobacco, and whatever they have at hand be their guests a local kinsman or a visitor from outside. More eventful social and ritual circumstances are marked by elaborate formal prestations and commensality proffered with elaborate etiquette (March 1987). This symmetrically reciprocal order takes highest structural form, as I have noted already, in the local social system of $d e$ facto exogamous moieties made up of patricians who exchange spouses in a system which can be accurately described as one of restricted exchange.

I want to emphasize, however, that at the same time that one can characterize Tamang social ethos as one of reciprocity among structural equals this does not constitute a total description of social relations. This ethos forms - as it were - in a field of social relations and practices which are in violation of this ethos. Accumulation, cheating, bickering, bitter factionalism are also a significant aspect of Tamang village life right along with harmonious interchange. In fact, the system itself entails structural asymmetries at any point in time between giver and receiver. My point here is simply that reciprocity is valued at times to the obfuscation of relations marked by inequality and asymmetry. Reciprocity must be seen as a value that emerges in a wider field of social relations and possibilities. The primacy of this value, however, is seen in Tamang predilections to moralize around issues of wealth and poverty. Those who accumulate or horde without a nod to redistribution or patronage are thought to be evil.

Social giving, though, is more than a fetish disguising real relations of accumulation and exploitation in a rhetoric of reciprocity. For Tamang, giving is a powerful act in that it establishes social relations in a specific form. It has the practical effect - as is well known - of engendering obligation and establishing control. In a quite real way, Tamang attempt to order the world by establishing obligatory exchange relations. Tamang ritually attempt to enclose social and cosmic forces into a rounds of reciprocity. Specialists are fastidious in being as inclusive as possible in their ritual offerings. They chant long lists of spirit beings that extend to the bounds of Tamang consciousness of the world. Likewise, at the simplest meals Tamang offer symbolic portions up to the gods and down to the evils with every being getting their share. When they sacrifice, Tamang distribute portions for all. In the grand scheme of things, Tamang draw a circle around a moral society of reciprocity either direct or redistributive. Those who lie outside the circle of a moral community are generally those whom Tamang conceive to be not only "other" but to have denied a fair share.

If Tamang struggle on one level to distribute shares in a reciprocating universe, the also imagine some human and extrahuman beings are left out. There is an antithetical backside to the social closure of reciprocal distribution peopled by a society of witches, poisoners, and evil spirits. Among the most prominent evils in the Tamang cosmos are the four mhiga whose principal definition is those who are left out. The haunting refrain of the exorcism of this metaevil of Tamang social imagination is, "In death, you did not get a share/In life, the portions were insufficient." Tamang recognize not only the logical potential but the reality of incompleteness to their reciprocal efforts. Lurking in those social margins is danger. To deny is to incur malevolent aggression in retum. In Tamang logic, those left out crave the good fortune of those with possessions. Evils like unwanted guests keep returning, demanding fair shares but providing nothing in return. Kami for Tamang villagers embody the social counterpart to spirit evils. Blacksmiths approach their Tamang patrons pleading, begging, demanding but not tied into the reciprocal relations that mark interchange with other Tamang. They are exploited and poor. In their relative want, Tamang imagine them to be perpetually covetous of Tamang good fortune and wealth. Their craving jealousy enters and ruins prosperity. An envious glance at a milking cow, a baby, a stocked granary can ruin, either sickening or poisoning. Kami women in particular are thought to afflict in this manner.

\section{Symmetrical and Asymmetrical Exchange}

From this outline of Tamang perspectives on outcaste Kami and their relations, I wish to raise in conclusion a comparative question. To what extent can Tamang outcasting of Kami and Hindu outcasting of untoucha-bles be understood as the same or different phenomena? I would argue that they are fundamentally different and that an 
examination of patterns of exchange allow; us to compare these systems. The most obvious quality of transactions in Hindu South Asia is that they are inherently asymmetrical. This asymmetry holds true whether one works from a Dumontian perspective (1970b) which sees the opposition of pure/impure as encoded in Hindu village exchanges or from critiques of this vantage (Marriot and Inden 1977). Most work on high caste communities in Nepal see the relations among castes as consistent with greater South Asian practice.

In Hindu caste communities, symmetrical exchanges across caste lines are rare but asymmetrical transactions abound. Asymmetry marks transactions in the so-called jajmani system. Transactions appear charged with ritual meanings, marking separation, difference, power, inequality, and rank whether: one works from a Dumontian scheme (1970) of castes forming a "religious society" or in Raheja's (1988) stress on the "ritual centrality" of land holding castes. In Raheja's village of Pahansu in Uttar Pradesh, for instance, Bangi or sweepers receive dan or gifts and thus "inauspiciousness" from their patrons in an array of ritual contexts; they "remove the "affliction"" of sick children during cures, and have ritual obligations at weddings and other social rites (1988). For Dumont (1970), Brahman and untouchable are linked through their mutual ritual dependence whereby the untouchable keeps the Brahman pure and thus ascendent and the Brahman communicates with the divine. Dumont bases his argument on the idea of wholeness whereby high and low are kept in systemic complementarity. My intent here is not to resolve debates in social anthropology of Indian villages but to make a comparison which is sustained no matter the interpretation of Hindu caste society to which one adheres. ${ }^{5}$

As I noted at the outset, Tamang and Kami do not articulate their interactions in a common cultural code. Tamang/Kami exchanges are antithetical to Tamang exchanges. Höfer captures the quality of Tamang/ Kami demeanor that suggests something quite different from reciprocal exchange:

The slightly plaintive intonation, feigning misery - a token of servility and thus an attribute of many untouchable castes - and the stereotyped allusions to his poverty appear only when Kami bargains [with] or visits his clients on holidays and begs for some alcohol. In the smithy, however, an impatient client is rebuked harshly and a Tamang asking a Kami for a cash credit is frequently compelled to flatter and beg for some time before getting the ten rupees asked for.

The Tamang call Kami a caste of beggars and liars and point out that the Kami are never satisfied with what they get, even in cases of over-payment. The Kami openly admit that begging is a habit of theirs, fulfilling thus the role expectation people have of them. (1976:353).

Relations are not mediated by either the ethos of reciprocity or of relative purity and inauspiciousness at work in the generation of Hindu caste asymmetry. Tamang exploit Kami to the highest degree but remain constrained in their dependence on iron work and field labor. Tamang have more power but Kami have some too. There is a social anonymity to the exchanges which allow Tamang to act in a purely exploitative manner toward Kami, extracting in a way that is thought to be unseemly within Tamang society.

Tamang villagers situate Kami at the margins of a closed society and according to a different cultural logic from that reported for highcaste Hindus. Kami do not carry pollutions in order that Tamang retain a purer position nor do they receive dan and it's concomitant "inauspiciousness." Tamang, moreover, do not respect the Brahman in any ritual sense. Ritual connections with either low or high are unelaborated and at best circumstantial. The lowness of Kami and their danger are best interpreted as an inverted refraction of symmetrical reciprocity.

Sahlins (1972) in his comparative work on exchange systems distinguishes between balanced, general, and negative reciprocity. Negative reciprocity is characterized by Sahlins as follows:

Negative reciprocity is the most impersonal sort of exchange. In guises such as 'barter' it is from our point of view the 'most economic' The participants confront each other as opposed interests, each looking to maximize utility at the other's expense." (195) 
Self-interest of this "most economic" type overtakes Tamang/Kami relations in direct contrast to a formal ethos of self-denial that is enforced in Tamang internal exchanges whether generalized or balanced. Kami ultimately end up with the short end of the stick because self-interest is limited by relative power and Tamang have the upper hand. In Tamang perspective, Kami occupy the position of outside insider and in this capacity can only be incorporated with the debility of being evil. The tag of defiling seems to be a secondary development through which Tamang relate to the historic rise of dominant Hindus Brahman and Thakuri.

\section{Counter Cultures}

Although Sahlins' scheme has some utility in understanding Tamang/ Kami relations as they are constructed in Tamang terms, it does not really provide for an understanding of exchanges in caste society. Sahlins like his predecessors, Mauss, Malinowski, and Levi-Strauss, has a two poled comparison of "primitive/modern." His typology does not fully encompass the kinds of valued transactions that govem Hindu village life. Transactions in village India, as have been demonstrated consistently (Tyler 1988), are inherently asymmetrical and of ritually valued materials ${ }^{7}$ among humans and between humans and the divine in a way that is markedly different from Tamang no matter what the interpretive stance one takes toward the issue of hierarchy. These asymmetrical exchanges constitute a moral economy but not one of balanced reciprocity, generalized reciprocity, or negative reciprocity.

Tamang outcastes and Hindu pani nacalne choi chito halmuparne jat are different even though the effects of their relations appear identical. These cultural boundaries are, I believe, significant but to discover their significance requires looking beyond Tamang/Kami interactions to the wider field of socio-political relations of Tamang in Nepal. In their historical resistence to domination by the state Tamang sustained a culture of symmetrical exchange, I would argue, as a form of counter culture. In other words, they reproduced an ethos of symmetrical exchange in the production of social solidarity that empowered them in resistance to state domination. It is not by chance that much of Tamang practice looks like the inverse of Hindu practice. (See Holmberg 2000; and Holmberg et. al. 1999). Ultimately Tamang culture as we witness it today formed in an integral way in a dialogic process with encompassing Hindu culture.

In conclusion, South Asia gains prominence in anthropological studies primarily because it was one of the few domains where an active comparative social anthropology unfolded, led in large measure by Dumont's contrast of an ideologically egalitarian West and a hierarchical Hindu South Asia. The emphasis of recent work on South Asia especially in American anthropology has been to undermine Dumont. On the one hand, there has been an empirical effort pursued from many directions to prove Dumont wrong and an attempt to uncover the true and essential nature of Indian culture and social practice. On the other hand, there has been an effort to deconstruct Dumont's formulation as an artifact of an Orientalist project to "essentialize" which in turn leads to "exoticizing," and "totalizing" as the hallmarks of the production of anthropological knowledge (Appadurai 1988) in Hindu South Asia. Most of these critiques are well-taken, yet, we should not abandon a comparative perspective that allows for difference outside of this narrow dichotomy. Moreover, the frame of the comparison in South Asia must move beyond the confines of the insular discourse of a Western/Hindu to include systems like that of the Tamang. Embedded in cultures like that of the Tamang is a sociologic and a culturologic that counters both poles in this dichotomy and colonizer and colonized get refigured in intriguing ways where for groups like the Tamang their overlords were the Shah and later Rana royalties along with their administrative operatives. The language of exchange and attention to everyday interaction may well lead us in the right direction to translate across different systems. It is precisely in the encounters of different cultures in Nepal outside of direct colonial rule by the West that we will be able to displace the opposition which has dominated the thought of postcolonial critics of the anthropological project, critics who fail to take seriously the differences in societies like Tamang and their caste neighbors and the role of localized colonizations embedded within the larger scheme of relations between the West and South Asia.

\section{ENDNOTES}

1. Much of the recent work on India's dalit or untouchables has concentrated on either acceptance of or resistance to formal caste ideology concerning 
their position (see Moffat 1979; Freeman 1979; Khare 1984). My concern is with social relations and the dominant Tamang construction of them.

2. Pseudonym.

3. Höfer (1979: 216) reports that Kami where he worked are not allowed to touch any part of the pipe.

4. Tamang specialists innumerate the following kinds of pollution in ritual incantations: mouth pollution, pollution of black bear meat, pollution of cannibalism, pollution of eating orphaned animals.

5. Raheja's critique of Dumont works from the logic that gift transactions do reproduce values but that those values are not those of encompassment or hierarchy at least as it is structured by Dumont in an opposition of pure and impure.

6. Cameron (1998) argues in a similar vein in her interpretation of low castes in western Nepal. Her emphasis on viewing exchange in the everyday interactions framed in relations of domination and subordination is consistent with my perspective here. I would only add that these "economic" relations are, however, directly related to cultural value and reproduce both each other in a non-reductive way.

7. As Gellner has noted in his own critique of Dumont, "The caste system requires Untouchables to be integrated as an essential defining feature and ritual role, the essence of which is that they must be different, excluded, and powerless." (1995:294).

\section{REFERENCES}

Ahearn, Laura M., 2001. Invitations to Love: Literacy, Love Letters, \& Social Change in Nepal. Ann Arbor, MI: The University of Michigan Press.

Appadurai, Arjun. 1998. Putting Hierarchy in its Place. Cultural Anthropology 3(1):36-49.

Azziz, Barbara Nimri. 1978. Tibetan Frontier Families. Durham, North Carolina: Carolina Academic Press.

Bourdieu, Pierre. 1977. Outline of a Theory of Practice. Cambridge: Cambridge University Press.

Cameron, Mary M. 1998. On the Edge of the Auspicious: Gender and Caste in Nepal. Urbana: University of Chicago Press.

Cohn, Bernard. 1968. Notes on the History of the Study of Indian Society and Culture. In Notes on the History of the Study of Indian Society. M. Singer and B. Cohn, eds. Pp. 3-28. Chicago: Aldine.
Dirks. Nicholas B. 2001. Castes of Mind: Colonialism and the Making of Modern India Princeton, NJ: Princeton University Press.

Dumont, Louis. 197ja. For a Sociology of India. In Religion, Politics, and History in India: Collected Papers in Indian Sociology. Pp. 2-18. The Hague: Mouten.

- 1970b. Homo Hierarchicus: An Essay on the Caste System. Chicago: University of Chicago Press.

Freeman, James. 1979. Untouchable: An Indian Life History. Stanford: Stanford University Press.

Fricke, Tom. 1995. History, Marriage Politics, and Demographic Events in Central Nepal. In Situating Fertility: Anthropology and Demographic Inquiry. S. Greenhalgh, ed. Pp. 202-224. Cambridge: Cambridge University Press.

Fürer-Haimendorf, Christoph von. 1972. The Sherpas of Nepal: Buddhist Highlanders. London: John Murray.

Gellner, David. 1995. Low Castes in Lalitpur. In Contested Hierarchies: A Collaborative Ethnography of Caste in the Kathmandu Valley, Nepal. D. Gellner and D. Quigley, eds. Pp. 264-297. Oxford: Clarendon Press.

Gellner, David, and Decan Quigley. 1995. Contested Hierarchies: A Collaborative Ethnography of Caste in the Kathmandu Valley, Nepal. Oxford: Clarendon Press.

Guha, Ranajit. 1983. The Elementary Aspects of Peasant Insurgency in Colonial India. Delhi: Oxford University Press.

Hodgson, Brian Houghton. 1971 [1848]. Aborigines of the Himalayas. In Essays on the Languages, Literature, and Religion of Nepal and Tibet, Part 2. Pp. 29-36. Varanasi: Bharat-Bharati.

- 1971 [1874]. Essays on the Languages, Literature, and Religion of Nepal and Tibet, Part 2. Varanasi: Bharat-Bharati.

Höfer, András. 1976. A Settlement and Smithy of Blacksmiths (Kami) in Nepal. Kailash 4(4):349-396.

- 1979. The Caste Hierarchy and the State in Nepal: A Study of the Muluki Ain of 1854. Innsbruck: Universitatsverlag Wagner.

Holmberg, David. 1989a. Observations on Hierarchy and Equality among Westem Tamang. American Anthropological Association Annual Meetings, Washington, DC, 1989a.

- 1989b. Order in Paradox: Myth, Ritual, and Exchange among Nepal's Tamang. Ithaca: Cornell University Press.

- 2000. Derision, Exorcism, and the Ritual Production of Power. American Ethnologist 27(4):927-949. 
Holmberg. David. Kathryn March, and Suryaman Tamang. 1999. Local Production/Local Knowledge: Forced Labour from Below. Studies in Nepali History and Society 4(1):5-64.

Hutton, J. H. 1973 [1943]. Caste in India. Bombay: Oxford University Press.

Khare, R. S. 1984. The Untouchable as Himself: Idcology, Identity, and Pragmatism among Lucknow Cambarus. Cambridge: Cambridge University Press.

March, Kathryn S. 1987. Hospitality, Women, and the Efficacy of Beer. Food and Footway 1:351-387.

Marriot, McKim, and Ronald B. Inden. 1977. Toward an Ethnosociology of South Asian Caste Systems. In The New Wind. K. David, ed. The Hague: Mouton.

Moftat, Michael. 1979. An Untouchable Community in South India: Structure and Consensus. Princeton: Princeton University Press.

Ortner, Sherry. 1973. Sherpa Purity. American Anthropologist 75:49-63

Passin, Herbert. 1955. Untouchahility in the Far-East. Monumenta Nipponica 11(3):247-267

Raheja, Gloria Goodwin. 1988. The Poison in the Gift: Ritual, Prestation, and the Dominant Caste in North India. Chicago: University of Chicago Press.

Sahlins, Marshall. 1972. Stone Age Economics. Chicago: Aldine-Atherton.

Sharma, Prayag Raj. 1977. Caste, Social Mobility, and Sanskritization: A Study of Nepal's Old Legal Code. Kailash 5:277-290.

Srinivas. M. N. 1952. Religion and society among the Coorgs of South India. Oxford: Clarendon Press.

Srinivas, M. N. 1966. Social Change in Modern India. Berkeley: University of California Press.

Toffin, Gérard. 1884. Unités de parenté, système d'alliance et de prestations chez les Tamang de l'Ouest (Nepal). Anthropos 81:21-45.

Tyler, Stephen A. 1986. India: An Anthropological Perspectivc. Prospect Heights, Illinois: Waveland Press.

\section{ALL IN THE FAMILY: MONEY, KINSHIP, AND THERAVADA MONASTICISM IN NEPAL}

David N. Gellner

(University of Oxford) and Sarah LeVine (Harvard University)

\section{Historical Background}

The figure of the monk-shaven-headed, ochre-robed, intent on enlightenment- is a key symbol in all Buddhism, but it is far more central in some forms or traditions than in others. In the traditional form of Buddhism of the Kathmandu Valley, Nepal, known as Newar Buddhism, the contrast between monasticism as a symbol and monasticism in practice is perhaps greater than anywhere. The story of the Buddha's renunciation was well known, in the Mahayanist version given in the Lalitavistara. The main shrines of Newar Buddhism nearly all contain statues of Shakyamuni Buddha himself and main Buddha shrine is usually flanked by the Buddha's two main monastic disciples,

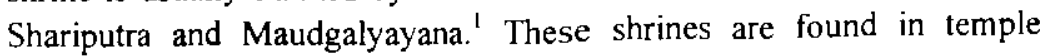
complexes, usually small courtyards given over to Buddhist monuments, known colloquially in Nepal Bhasha (Newari), the local language of the Kathmandu Valley, as bahah or bahi, and honorifically by the Sanskrit and Pali term, vihara. In other words, from the point of view of the tradition, these sacred Buddhist courtyards are monasteries and the ritual specialists who inhabited and owned them are monks. And yet there are no full-time monastics in Newar Buddhism. Instead there is a sacerdotal caste of married domestic and temple priests, the Vajracharyas and Shakyas, the male Vajracharyas being the only ones entitled to be domestic priests, the menfolk of the two groups together providing the temple priests of the Newar Buddhist viharas. Thus Vajracharyas and 